\section{Military Technical College Kobry El-Kobbah, Cairo, Egypt}

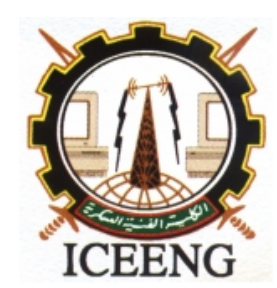

\author{
$7^{\text {th }}$ International Conference \\ on Electrical Engineering \\ ICEENG 2010
}

\title{
MAINTENANCE OF HIGH VOLTAGE EQUIPMENT IN HIGH VOLTAGE SUBSTATIONS
}

\begin{abstract}
By
Nenad Trkulja, M.Sc.El.Eng. JP "Elektromreža Srbije"

Belgrade, Serbia

\section{$\underline{\text { Resume: }}$}

Due to the increasing influence of power equipment maintenance to the price of delivered/undelivered energy, this paper provides the categories, strategy and policies of the maintenance. It also defines the maintenance activities, the ordinary required maintenance and optimal intervals of the maintenance. The paper defines the maintenance planning in compliance with the confronted requirements of the exploitation and maintenance as well as the availability of plants elements. Based upon the above, a model is provided for the calculation of the life cycle costs (LCC).
\end{abstract}

\section{Keywords:}

Maintenance, corrective, prevention, intervention, plan, status, revenue, cost, policy, strategy, reconstruction. 


\section{Introduction:}

All the activities done on some technical equipment represent a kin of maintenance. The scope of work done in the certain type of the equipment varies from case to case, but there is no device which can be used continuously without any maintenance. The maintenance includes all activities which are necessary to bring the equipment in the operating state. In the power sector, we use a slightly changed definition of the maintenance which observes it from the economic point of view.

The maintenance in power sector includes a series of the activities with the objective to provide that the substations permanently satisfies all the requirements relating to the technical characteristics, availability and annual expenditures and which are performed taking into account the position of the substation in the electric energy system.

The maintenance may be divided in two basic groups, the corrective maintenance and the preventive maintenance. As regards the maintenance strategy there are intervenient and planned maintenance.

With an adequate maintenance strategy a user may provide the conditions for a long life of a substation, and its low costs already projected in the design preparation phase. The designer is responsible only for the design and project management, and the user have the opportunity to increase the maintenance effect. Very often, in the practice this aspect is not given a due attention because in design preparation phase and decision making after the tender procedures, the priority is given to the low investment costs. The invested money is only a part of the total costs incurred in the substation life cycle. The costs for substations include the operation, maintenance and repair costs in case of failure. etc. This is very important for the substations, because their projected life cycle is over 50 years. The share of the total Life Cycle Costs (LCC) in the substations is about $50-100 \%$ of the investment costs.

\section{General:}

The profit achieved during the substations life cycle (LCP-Life Cycle Profit) represents a difference between the earnings and expenditures (LCC-Life Cycle Cost) during life cycle of the substation. It should be positive. To achieve this, various strategies are implemented in the maintenance of the substations:

\subsection{Intervenient maintenance}

This is the most frequently applied type of the maintenance. Under this type of the maintenance a substation is in the operation until a defect occurs or until it needs to be disconnected because of the safety reasons. At that moment, the defect is repaired and the substation is immediately put into operation. Although, this type of the maintenance is less economic, sometimes we are forced to apply it. 


\subsection{Planned maintenance}

This type of the maintenance includes the operation of the substation works for a certain period of time and then it is disconnected so that certain planned repairs may be executed. Then it may happen that some components are replaced before they were completely exploited which results in the increase of costs. Despite the previously stated the total costs of the planned maintenance are lower than the costs of the intervenient maintenance.

\subsection{Maintenance based on condition}

The most economic strategy of the maintenance is the one which results from the permanent monitoring of the substations conditions. This strategy minimizes the costs of the maintenance and rises the substation availability. The replacements and repairs are planned in advance and they are executed according to the planned time schedule. A new substation should always be maintained in compliance with the strategy based upon its conditions, because in that case the maximum availability and the longest life cycle are assured at the lowest costs. With the aging of the substation, an application of a different maintenance strategy may prove to be justified. Various checks and measuring are used to determine the actual status of the equipment and some of its vital components. The maintenance itself which is based upon the control of the equipment conditions is not associated with the fixed time intervals. The data on the substations reliability are the indicators of the maintenance quality.

\section{Maintenance policy:}

The most important goal for each substation is the attainment of its maximum productivity. It means that in the substation operation and maintenance taking in account its characteristics and conditions, we need focus to the following:

- Minimizing of Life Cycle Costs,

- Applying the maintenance policy harmonized with the market and

- Setting high goals to be achieved by timely and appropriate maintenance.

In addition to the above the substation maintenance may be caused by:

- importance,

- environment,

- operating conditions,

- location and

- costs of substation disconnection.

\subsection{Importance}

The importance of some substations is valued depending on their place in the transmission system, the existence of alternatives, etc. 


\subsection{Environment}

The environment imposes various problems to the maintenance which may be as follows:

- Salt pollution near sea coastal area,

- Snow and big number of rainy days,

- High humidity,

- Fast growing of vegetation.

Middle voltage and some high voltage equipment my be completely installed indoor and that results in lower maintenance costs and the possibility to perform the maintenance during the whole year.

\subsection{Operating conditions}

The way of the specific equipment maintenance depends on the operating conditions for the specific equipment in the substations, the number of $\mathrm{CO}$ cycles, short circuit current on the place of the installation of equipment....

\subsection{Location}

The location of the substation requires the engagement for the setting of its external appearance. The requirement differs for the urban area and for the rural area.

\subsection{Cost of stopping of substations}

The level of the maintenance requests is directly related to the costs of the stoppage which the transmission company has. For that reason it is very important to determined the real costs occurring in case of the substation operation stoppage.

\section{Maintenance:}

The maintenance includes a set of activities necessary to bring the equipment into the planned status. The maintenance activities shall be carried out under the maximum safety conditions. The maintenance may divided into the preventive and corrective maintenance.

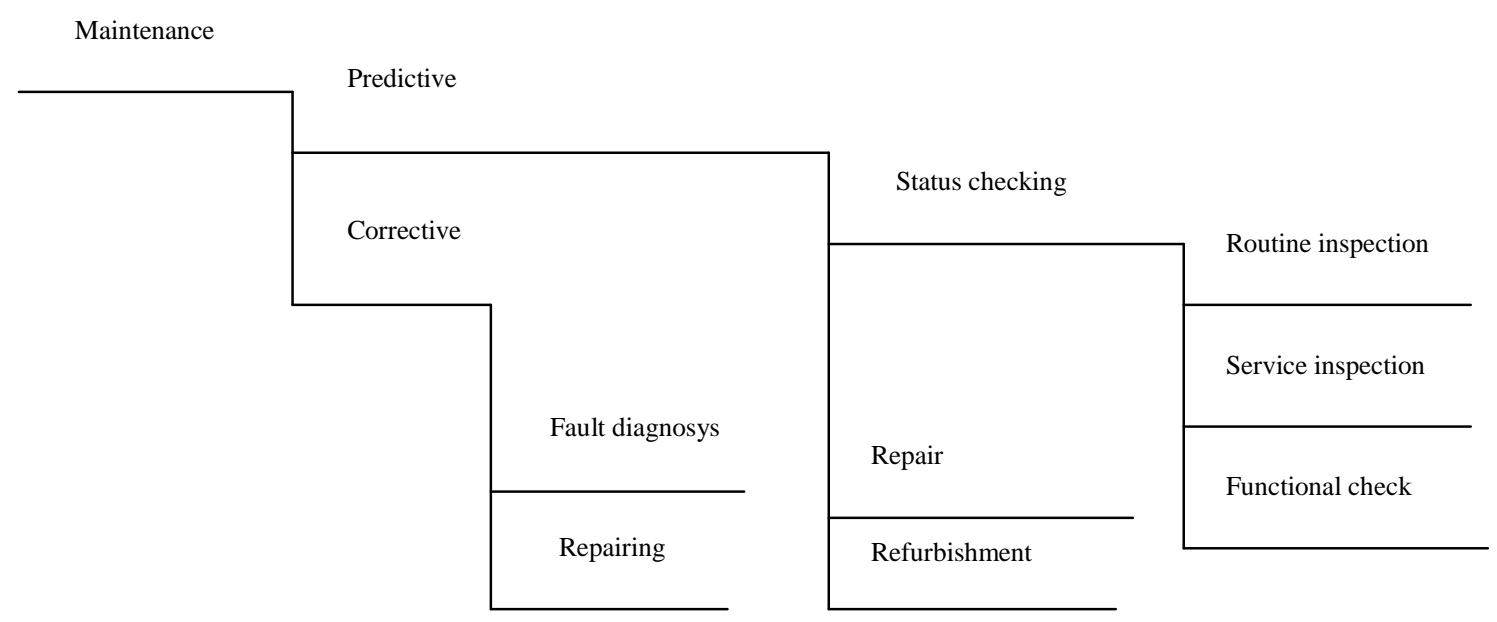

Figure 1: Types of maintenance 


\subsection{Preventive maintenance}

It is performed according to the time intervals defined in advance, or according to the specified criteria and its it is aimed at a minimizing the possible defects in the substation. Although this maintenance is mostly performed pursuant to the recommendations of the manufacturer of the equipment, it also includes some activities which are not necessary. To determine precise time schedules for the performance of the maintenance it is necessary to make inspections and measuring to determine the real conditions of apparatuses. Then the preventive maintenance is based on the checking of conditions and not on fixed time intervals.

Preventive maintenance is divided into Checking of conditions, Repairs/overhaul and Refurbishment.

\subsubsection{Checking of conditions}

The checking is divided into Routine inspection, Service inspection and Functional check. Checking should be done in fixed time intervals.

- Routine inspection is routine checking, and it is done by looking at, hearing, smelling or by some simple measuring while the plant is operating.

- Service inspection is an enhanced testing which requires the preparatory activities and it shall be effected by the trained and experienced stuff.

- Functional check provides the information whether the equipment operates in a proper way, and what is its state. It consists of general check, testing, cleaning and lubrication of devices.

The checking of state may also include thermo graphic measuring, measuring of partial discharging, vibrations, gas analysis, corona measuring etc...

\subsubsection{Repair}

It is complex activity which has to be done during the maintenance in order to repair functional and other faults of the equipment (i.e. replacement of the over aged components...). The Repair includes also all anti corrosive measures. The intervals between repairs are determined on the basis of the checking of the state. The repairs are usually undertaken after 10-12 years of the use of the equipment.

\subsubsection{Refurbishment}

If we want the substation to attain the quality of operation enabling it to meet the requirements regarding the effectiveness, availability, appearance and economic operation we have to refurbish it. It usually requires a total disassembling, cleaning, replacement of over aged or damaged parts, necessary surface protection and devices tests. After the substation is refurbished it is brought to the level which is comparable with the status of a new one. The interval between refurbishments are defined on the basis of the state checking but in practice the usual intervals between refurbishments are 20 - 25 years.

\subsection{Corrective Maintenance}

The corrective maintenance is applied after the occurrence of an accident or faults 
in the equipment and its goal is to bring substation in state in which it may perform its function.

\subsubsection{Fault diagnosis}

This diagnosis determines the real state of equipment after a fault occurrence and the work needed to bring a substation to normal work.

\subsubsection{Repairing}

It is one part of the corrective maintenance and it is done based on the data from the fault diagnosis.

\subsubsection{Maintenance based on prediction of equipment state}

These activities confirm the characteristics of the specific elements of the system. The activities which are undertaken start with a visual examining and their purpose is to confirm certain specific characteristics and functionality. The activities which will be done immediately after this check are considered as a part of this type of maintenance.

\section{Average maintenance requirements}

Intervals for some maintenance works based on the experience from substations:

\section{For substations:}

Type of maintenance: interval:

Routine inspection

Functional check

Repair

Refurbishment

$$
\begin{array}{ll}
1-30 & \text { days } \\
1-4 & \text { years } \\
8-12 & \text { years (depending checking of state) }
\end{array}
$$$$
\text { state) }
$$

\section{For overhead lines:}

Type of maintenance:

interval:

Inspection in connection with maintenance $\quad 8$ years

Testing resistance of earthling

Service inspection

Inspection of tower stands
8 years

1 years

8 years

\section{For protective relays:}

Functional checks

- Relay for $400 / 110 \mathrm{kV}$ lines

- Other relays

- Communication systems interval:

$\begin{array}{ll} & 2 \text { years } \\ 4 & \text { years } \\ 2 & \text { years }\end{array}$




\section{Optimal intervals for maintenance}

The most optimal major inspections and refurbishment are those which are based on checking of the substation. That is why the intervals between functional checks must always be analyzed. The minimum on the curve of the annual maintenance costs and faults costs $(\mathrm{dP} / \mathrm{dT}=0)$ define the point of the optimal interval for the maintenance.

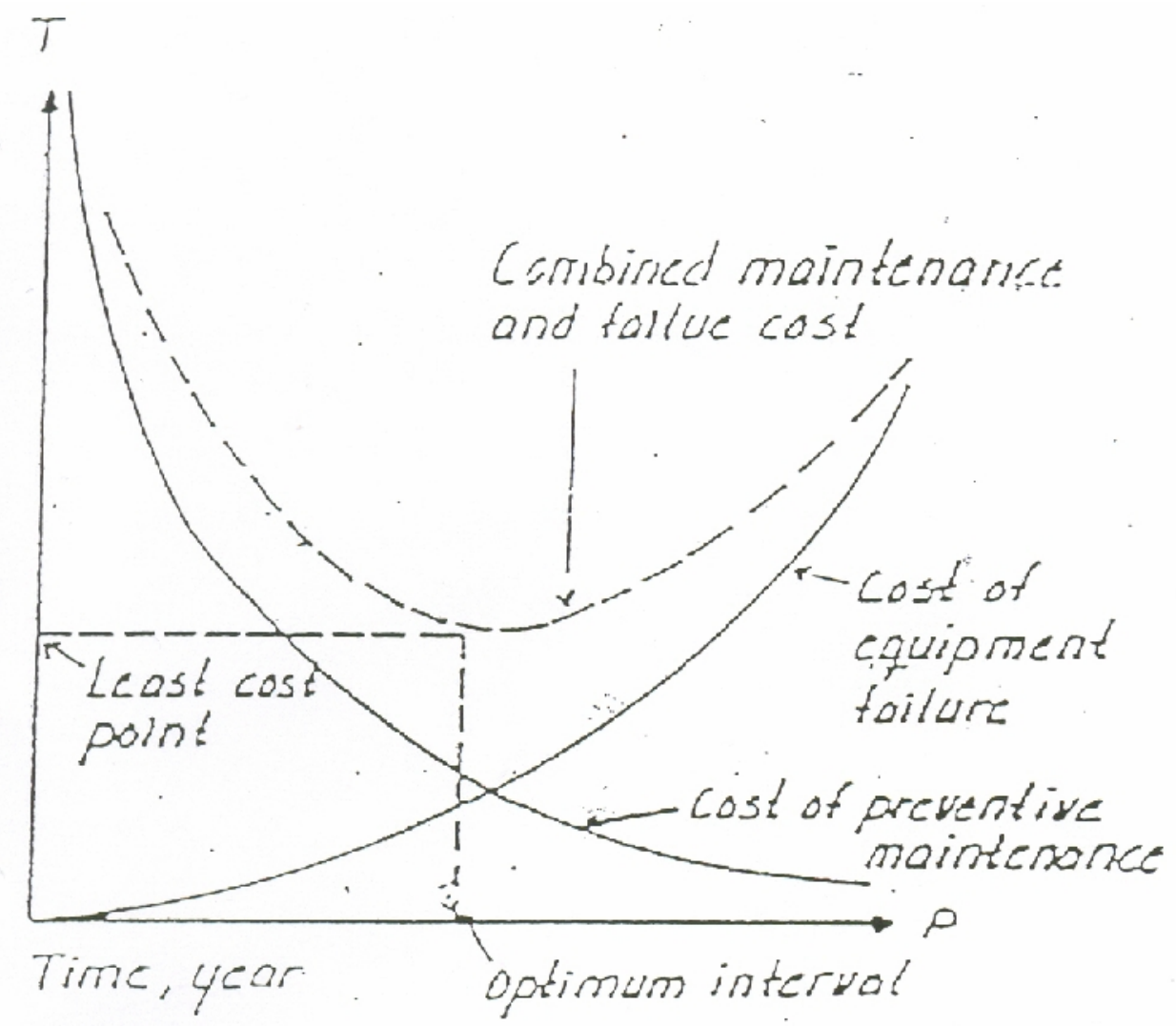

Figure 2. Curve of annual costs of maintenance and fault costs

\section{Planning of maintenance}

The most important task of the Maintenance Department is to maintain the substation operation. That is why it may be considered as an additional activity for the exploitation department. The exploitation department and maintenance department are in some aspects opposed.

The exploitation requests are:

- To make substations disconnections as short as possible

- To make losses as small as possible 
- To keep safety on the highest level

- To disconnect equipment during low load periods

The maintenance requests are:

- Timely preventive maintenance based on checking of conditions

- To make costs as small as possible

- More efficiency work

The planning system assures the safety in the substation operation and its more efficient maintenance. It should provide correct answers to the following questions:

- What has to be done?

- Who will do that?

- On which equipment the maintenance should be done?

- What are necessary spare parts?

- When and how often the maintenance works need to be executed?

These information's should be taken into account when the maintenance plans are made.

\section{Availability:}

The scope of the necessary maintenance after the full load operation during a certain period of time depends on qualitative characteristics of equipment and it also defines the level of the availability. It can be divided in three groups: the level of readability, the scope of maintenance and the scope of the maintenance support.

The availability $(\mathbf{R})$ is usually calculated as follows:

MTBF - Mean Time Between Faults

$$
\mathbf{R}=\frac{\mathbf{R T B F}}{\mathrm{MTBF}+\mathrm{MTTR}+\mathrm{MWT}}
$$

MTTR - Mean Time To Repair

MWT - Mean Waiting Time

The availability actually represents a number of days in a year minus time needed for the maintenance and waiting for the maintenance. During the rest of the time the substation is in such conditions that it can operate if necessary.

If the availability is calculated on the basis of the real data about the operating time and stoppage time we use next equation:

$$
R=\frac{\text { Operating time }}{\text { Operating time }+ \text { Stoppage time }}
$$


In this case stoppage time is the sum of time needed for the repair and time we are waiting for the repair. The time spent for other reasons is not taken into account. If we also calculate time lost for other reasons, we come to the utilization level.

\section{Relaibility (MTBF, MTTF)}

The reliability is measured by the average time between faults or by time until a fault occurs, MTBF or MTTF (MTBF includes also time for a repair), and they mark the same value.

The factors influencing the reliability are:

- designing

- production

- erection

- preventive maintenance

\section{Abillity for maintenance (MTTR)}

The ability for maintenance is measured by the average time for a repair MTTR. The time for a repair shall include time needed for the execution of other maintenance activities (time of stoppage of equipment because of maintenance). In addition, some maintenance activities may be effected without disconnection, like monitoring of the equipment conditions.

For a longer period of time MTTR is:

$$
M T T R=\frac{\text { Total time needed for maintenance }}{\text { Number of events }}
$$

\section{Maintenance support}

Mean waiting time, MWT is a safety measure of delivery, namely the measure of the maintenance organization efficiency. This includes time from a fault occurrence when the maintenance staff is alarmed, when the tools and spare parts are gathered, when a transport from the workshop up to substation is effected... During this time there is no work on the equipment - everything is under stay.

The important factors which influence on the maintenance support are spare parts, tools and instruments, competent staff, documentation and transport. 


\section{Availability measuring)}

\begin{tabular}{|c|c|c|c|c|}
\hline \multirow[b]{2}{*}{ 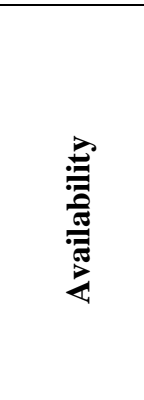 } & \multirow{2}{*}{ 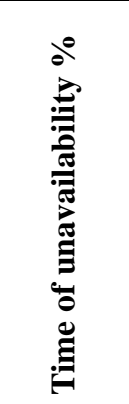 } & \multicolumn{3}{|c|}{ UNAVAILABILITY } \\
\hline & & 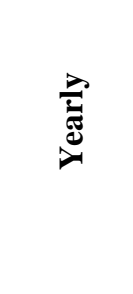 & 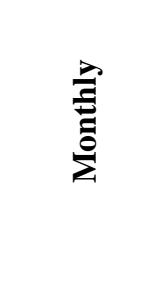 & 㓂 \\
\hline 0 & 100 & $8760 \mathrm{~h}$ & $720 \mathrm{~h}$ & $24 \mathrm{~h}$ \\
\hline 50 & 50 & $4380 \mathrm{~h}$ & $360 \mathrm{~h}$ & $12 \mathrm{~h}$ \\
\hline 90 & 10 & $876 \mathrm{~h}$ & $72 \mathrm{~h}$ & $2.4 \mathrm{~h}$ \\
\hline 99 & 1 & $88 \mathrm{~h}$ & $7 \mathrm{~h}$ & $14.4 \mathrm{~min}$ \\
\hline 99.9 & 0.1 & $8.8 \mathrm{~h}$ & $43 \mathrm{~min}$ & $1.44 \mathrm{~min}$ \\
\hline 99.9999 & 0.0001 & $32 \mathrm{sec}$ & $2.6 \mathrm{sec}$ & $0.086 \mathrm{sec}$ \\
\hline
\end{tabular}

\section{Calculating of Life Cycle Costs (LCC)}

The analysis of the Life Cycle Costs should be done during planning and designing of new substations, evaluation of bids during tender procedures, comparison of various maintenance activities and making decisions about refurbishment of substations. It consists of the following phases:

- Defining analysis target

- Defining of all requirements and conditions

- Choosing selected variants

- Defining analysis model

- Comparison of options

- Presenting proposals

The analysis target shall be clearly defined. The appropriate discount rate for a discounting of substations values need to be used taking into account that the depreciation period for lines is about 50-60 years, and for substations - about 30 years. Also the national and international standards shall be obeyed and the maintenance conditions shall be analyzed, namely the requested resources needed for the maintenance shall be defined. These include competent staff, vehicles, tools, documentations...

A model shall be determined for each analysis and it shall include all main factors and costs. The model shall be reliable, simple and easy to use.

An example of one simple model:

$$
\mathbf{L C C}=\mathbf{I}+\mathbf{O}+\mathbf{M}+\mathbf{U}-\mathbf{R}
$$


$\mathbf{I}=$ investment costs

$\mathbf{O}=$ operating costs (stuff, fuel, losses)

$\mathbf{M}=$ maintenance costs (preventive. corrective)

$\mathbf{U}=$ costs of unavailability (energy which is not transferred, penalty, rise of losses in transmission...)

$\mathbf{R}=$ rest value

Rest value $(\boldsymbol{R})$

Rest value of substation at the end of the period of analysis. The costs are shown as annual costs.

\section{Investment Costs (I)}

They are:

- Value of equipment in substation

- Designing, making documentation, erection, testing and training

- Initial spare parts, tools and apparatus,

- Profit which is not gained during erection

\section{Operating Costs $(\mathrm{O})$}

These costs include the costs of the operational staff, fuel, losses...

\section{Maintenance Costs $(M)$}

They include the staff wages, expenses of the staff executing the works, materials and special costs.

\section{Costs caused by unavailability $(U)$}

- Costs due to increased losses in transmission grid

- Costs due to interruption in the supply of consumers

The analysis of the life cycle costs of a substation we may achieve as follows:

- To reduce maximum the total Life Cycle Costs

- To get long and reliable operation of a substation

High level of availabilityThese costs include the costs of the operational staff, fuel, losses...

\section{Maintenance Costs $(M)$}

They include the staff wages, expenses of the staff executing the works, materials and special costs.

\section{Costs caused by unavailability $(U)$}

- Costs due to increased losses in transmission grid

- Costs due to interruption in the supply of consumers

The analysis of the life cycle costs of a substation we may achieve as follows:

- To reduce maximum the total Life Cycle Costs

- To get long and reliable operation of a substation

- High level of availability 


\section{Maintenance manuals}

All maintenance works shall be carried out under the maximum safety conditions and according to the relevant standards. All maintenance requirements are usually recommended by suppliers regarding the suggested intervals between maintenance works. The experience in the maintenance will help us to extend the intervals between the maintenance activities and to reduce the number of these activities.

It is very important to have detailed and comprehensive manuals which will be a basis for the works of the maintenance stuff. These manuals are necessary for a high quality planning of the maintenance, because the scope of some activities cannot be estimated if it has not been previously defined what activities are to be executed.

\section{Conclusion}

The rise in energy prices is followed by increased requests for the energy efficiency, causing also the increased demands for the efficient maintenance. The importance of a precise calculation of the exploitation costs and unavailability costs of some equipment is nowadays very significant, in particular in the light of the splitting of the activities within the electric power industry. Therefore the accuracy of the inputs used for the strategic planning depends on the accuracy of the above calculation.

\section{Literature}

1. Maintenance. Procurement and using of materials - Planning and managing, IPA Energy Consulting 2004.;

2. Blue book“ - (Look in maintenance work for substations and lines), PE Elektroistok; 